\title{
Resolução de conflitos e a compreensão emocional em crianças do Pré-Escolar
}

\author{
Conflict Resolution and Emotional Understanding in Preschool Children
}

\author{
Glória Franco*, Eduína Rodrigues, \\ *Universidade da Madeira,
}

\begin{abstract}
Resumen
O estudo tem como objectivo compreender a capacidade de resolução de conflitos e sua relação com a compreensão emocional em crianças do pré-escolar. A amostra é constituída por 27 crianças, com idades entre 3 e 5 anos, da Ilha da Madeira-Portugal. Os instrumentos utilizados foram: questionário dados sociodemográficos; entrevista semiestruturada; teste compreensão emocional (TEC-Test of Emotion Comprehension). Os resultados indicam que as crianças apresentam dificuldades em identificar situações de conflito e no que concerne à capacidade de compreensão das emoções, a maioria das crianças apresentaram resultados positivos, nomeadamente no reconhecimento das emoções e na compreensão das causas externas das emoções.
\end{abstract}

Palabras clave: Gestão de conflitos, Compreensão emocional, Ensino pré-escolar Abstract

The study aims to understand the ability of conflict resolution and its relation to emotional understanding in preschool children. The sample comprises 27 children, aged 3 to 5 years, from Madeira Island, Portugal. The instruments used were: sociodemographic questionnaire, semi-structured interview and an emotional comprehension test (TEC-Test of Emotion Comprehension). The results indicate that children have difficulties in identifying situations of conflict and regarding the ability of emotions understanding, most children showed positive results, particularly in the recognition of emotions and understanding of external causes of emotions.

Keywords Conflict resolution, Emotional understanding, Preschool education

\section{Introdução}

Em 1997, Verbeek \& de Wall realizaram o primeiro estudo etológico centrado na resolução de conflitos em chimpazés (Pan troglodytes) em cativeiro, dando evidências de uma aproximação e troca de comportamentos amigáveis entre oponentes. Estes autores verificaram um aumento da tendência afiliativa gerada por episódios de conflito, em que os oponentes se procuravam ativamente. A estas interações amigáveis chamaram reconciliação, baseando-se no pressuposto de que funcionam para restaurar a tolerancia e reparar os danos no relacionamento dos oponentes. (Aureli, Cords, \& Van Schaik, 2002). O termo carrega a implicação funcional de ser um mecanismo para reparar uma relação social que foi perturbada no conflito anterior, ou seja, atenua as consequências negativas do conflito (Preuschoft, Wang, Aureli, \& de Waal, 2002).

As experiências com os pares constituem um contexto de desenvolvimento fundamental para as crianças, no qual adquirem múltiplas capacidades que vão provavelmente influenciar a sua adaptação ao longo da vida. Consequentemente, os pares são influentes agentes de socialização, contribuindo, juntamente com a família e a escola, para uma progressiva adequação do bem-estar sócio cognitivo (Rubin., Bukowski, \& Parker, 1998).

Por um lado, parece ser necessário haver um mínimo de interação social com os pares, para que o individuo desenvolva a capacidade de compreender que o outro tem uma perspetiva, uma intenção ou uma ideia distinta da sua (Hollos \& Cowan, 1973). Por outro lado, a capacidade para reconhecer os estados mentais dos outros, é um fator importante no sucesso das interações sociais (Wellman, Cross, \& Watson, 2001), podendo estar relacionado com a competência social (Walker, 2005).

No complexo sistema social das crianças de idade pré-escolar, as interações entre pares contribuem de modo considerável para o desenvolvimento cognitivo bem como para a eficiência do seu funcionamento enquanto adultos (Hartup, 1992). Consequentemente, um individuo que não desenvolva um conjunto de aptidões sociais e não seja aceite socialmente, que seja frequentemente agressivo e incapaz de manter relações próximas ou positivas com os outros, pode dificultar a adaptação social nas fases seguintes do desenvolvimento (Hartup, 1992).

Uma criança eficiente na organização e coordenação dos recursos individuais poderá, em principio, estar melhor preparada para se adaptar a oportunidades e desafios futuros (Waters \& Sroufe, 1983). No entanto, esta adaptação só é indicadora de competência se implicar alterações no desenvolvimento do indivíduo, facilitando a sua integração social.

As crianças interagem com os pares para ganhar e manter o acesso aos recursos limitados, sendo que algumas das competências básicas de resolução de conflitos, a par da competência social, começam a desenvolver-se durante os anos pré-escolares (Shantz, 1987).

Segundo Green e Rechis (2006), a criança socialmente competente é capaz de atingir o equilíbrio entre os seus objetivos sociais e a manutenção de relações sociais positivas, ao utilizar uma combinação de estratégias coercivas e pró-sociais na resolução de conflitos (Hawley, 1999), enquanto as crianças menos 
competentes socialmente, têm maior dificuldade em interagir de forma efetiva com as outras, podendo vir a ser rejeitadas pelo grupo (Green \& Rechis, 2006).

Os indivíduos que sabem utilizar estratégias diversificadas e adaptadas às situações de conflito são, provavelmente, os mais competentes, na medida em que alcançam os seus objetivos de forma socialmente mais eficaz.

Este estudo tem como objectivo entender a capacidade que as crianças do pré-escolar têm de perceber os conflitos, as suas causas e a capacidade de pensar em estratégias de resolução de conflitos e qual a sua relação com a capacidade de lidar e gerir as emoções.

\section{Participantes}

\section{Método}

O presente estudo foi realizado num infantário da Região Autónoma da Madeira, com uma amostra composta por 27 crianças que frequentam a sala de jardim-de-infância, com idades compreendidas entre os 3 e 5 anos. De entre estes, seis eram raparigas e vinte e um rapazes. Dentro da faixa dos três anos, quatro são raparigas e onze rapazes, dentro da faixa dos quatro anos, duas são raparigas e oito rapazes e na faixa dos cinco anos existem apenas dois rapazes.

\section{Instrumentos}

Os instrumentos de recolha de dados usados neste estudo foram os seguintes:

- Questionário de dados sociodemográficos. Elaborado para levantamento dos dados relativos à criança e ao seu contexto de vida e foi preenchido pelos pais;

- $\quad$ Entrevista semiestruturada. Foi preparada uma entrevista para analisar e avaliar a compreensão das emoções e a capacidade da criança em gerir os conflitos. Na realização da entrevista foram utilizadas imagens que representavam três situações de conflito, exclusão, agressão física e agressão verbal, e para cada imagem havia dez questões, nas quais se pretendia que as crianças observassem, refletissem e falassem sobre o conflito apresentado e apresentassem estratégias eficazes para resolverem os conflitos. Antes da realização da entrevista foi efetuado um pré-teste com um outro grupo de crianças da mesma faixa etária em outro estabelecimento de forma a certificar-se de que as imagens utilizadas correspondiam aos conflitos que se quería representar. O pré-teste teve resultados positivos, uma vez que as crianças conseguiram identificar os conflitos esperados.

TEC (Test of Emotion Comprehension) de Pons, Harris e de Rosnay (2004), nomeadamente a versão portuguesa traduzida por Roazzi, Dias, Minervino, Roazzi e Pons (2008). O TEC está dividido em blocos de histórias em ordem pré-estabelecida, apresentando os seguintes contextos: 1) o reconhecimento das emoções, baseado nas expressões faciais; 2) compreensão das causas externas das emoções; 3) compreensão do desejo despertado; 4) compreensão das emoções baseadas em crenças; 5) compreensão da influência da lembrança em circunstâncias de avaliação de estados emocionais; 6) compreensão das possibilidades de controlar as experiências emocionais; 7) compreensão da possibilidade de esconder um estado emocional; 8) compreensão da existência de múltiplas ou até contraditórias (ambivalentes) respostas emocionais; 9) compreensão de expressões morais. Para a análise, um ponto é atribuído para cada componente respondido corretamente. Cada criança poderá obter no máximo 9 pontos e no mínimo 0. A partir destes resultados, pode ser detetada uma evolução de uma competência meta-emocional que pode ser distinta em três áreas de desenvolvimento: 1) Categorização das emoções em relação à sua natureza; 2) Compreensão das causas das emoções; 3) Controle das emoções (Roazzi, et al., 2008).

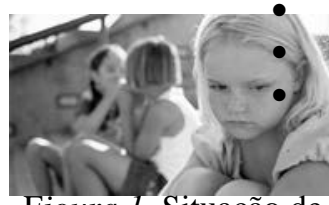

Figura 1. Situação de Conflito: Exclusão

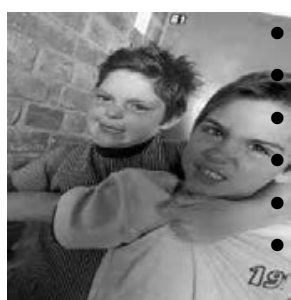

Figura 2. Situação de Conflito: Agressão Física

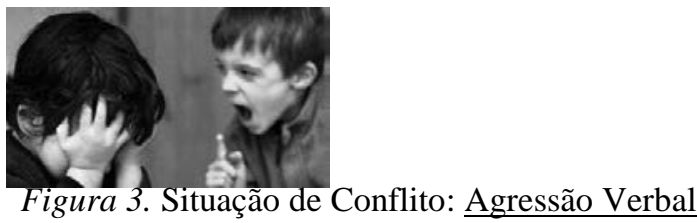

\section{Procedimentos}

Em primeiro lugar realizaram-se as entrevistas a todas as crianças e só depois destas estarem concluídas é que foi passado o TEC. As entrevistas decorreram durante duas semanas na escola frequentada pelas crianças, durante um período letivo (manhã ou tarde) e a aplicação do TEC ocorreu na semana seguinte, no período letivo da tarde. Cada criança reuniu-se individualmente com a investigadora num gabinete ou espaço calmo. As entrevistas foram precedidas de um pequeno diálogo, para colocar as crianças descontraídas e à vontade e onde era explicado o que estas teriam de fazer.

Nas entrevistas foram apresentadas as imagens às crianças, seguindo sempre a mesma ordem (exclusão, agressão verbal e agressão física) e para cada imagem colocadas as questões estabelecidas (Tabela 1). Todas as entrevistas foram gravadas em áudio, tendo em conta a manutenção da confidencialidade e do anonimato dos participantes, para posterior transcrição e codificação.

Terminadas as entrevistas, estas foram transcritas, lidas e organizadas. Foi necessário realizar uma análise de conteúdo das respostas das crianças nas entrevistas, com o intuito de colher critérios para se poderem agrupar. Desta forma, de acordo com os objetivos do 
estudo foram definidas categorias e subcategorias para a categorização das respostas dadas pelos sujeitos da amostra nas entrevistas (Tabela 1).

De seguida, as respostas foram ordenadas e agrupadas, fazendo-se diversas leituras e comparações das mesmas na tentativa de verificar se os resultados vão de encontro à literatura e se surgiam dados novos e interessantes para analisar, para posteriormente comparar com os resultados de outras investigações.

A partir destas categorias e subcategorias foram analisadas e cotadas todas as entrevistas de forma individual. A partir da somatória de todas as categorias foi possível atribuir uma cotação para determinar a capacidade de gestão de conflitos, fazendo uma comparação entre os indivíduos da amostra e tendo como base o enquadramento teórico foram criadas três dimensões de forma a fazer uma análise mais pormenorizada. Essas dimensões foram as seguintes: Capacidade de identificação de conflitos que permite agrupar as seguintes categorias: identificação do conflito, descodificação causal e atribuição causal do conflito; Capacidade de compreensão das emoções associadas à gestão de conflitos que permite agrupar as categorias de identificação das emoções, compreensão das emoções (emoção negativa e positiva); e a Capacidade de gerar soluções que está associada às categorias de previsão de acontecimentos, conceção de um plano para a solução do problema e apresentação de soluções para situações negativas e positivas. Finalmente para uma melhor comparabilidade dos dados da entrevista, a pontuação bruta foi estandardizada em notas $\mathrm{T}$ (Media (M) $=50$ e Desvio Padrão $(\mathrm{DP})=10$ ).

Após a recolha de dados e quantificação das entrevistas foi elaborada uma base de dados que permitiu uma análise dos dados obtidos de todos os instrumentos utilizados. Esta análise foi feita através do programa estatístico quantitativo de tratamento de dados - SPSS (Statistical Package for Social Sciences), versão 20.

\section{Resultados \\ Análise descritiva das entrevistas}

A nível da identificação do conflito constatou-se que mais de metade do grupo (62\%) identificou o conflito esperado ou outro tipo de conflito, no entanto, (38\%) não conseguiu identificar nenhum conflito. Das crianças que identificaram conflitos, $16 \%$ não identificaram o conflito esperado, mas identificaram outros, como por exemplo, na imagem de exclusão indicaram que "não partilha”, “a menina não quer brincar com os meninos”, tiveram a capacidade de inverter a situação. Na imagem de agressão verbal indicaram, por exemplo, que o menino "está chorando" e na imagem de agressão física indicaram, por exemplo, que "um menino está a agarrar o braço dela”.

Quanto à descodificação causal verificou-se que 58 $\%$ das crianças conseguiu descodificar a causa dos conflitos, seja através de estímulos do contexto apresentados na imagem, seja através de expressões faciais ou através de ambos fatores. É importante referir que $42 \%$ não conseguiu descodificar a causa do conflito. A maioria das crianças descodifica a causa do conflito através da observação das expressões faciais, 27\% (por exemplo, "pra cara delas”, "ela tem os olhos virados para ali e a cara também e o nariz também”) ou através de estímulos de contexto, 17\% (por exemplo, "para a praia”), apenas $14 \%$ das crianças descodificou a causa através das expressões faciais juntamente com os estímulos do contexto (por exemplo, “esta menina está triste porque não tem ninguém”, "o menino ficou assustado com os gritos deste menino”, "eu vi a senhora apertar o pescoço dela”.

No que concerne à atribuição causal do conflito verificou que $31 \%$ das crianças atribui a causa do conflito a motivos relacionais (por exemplo, "elas não querem ir brincar com ela”, "não quer brincar com ele”), $28 \%$ atribui a causa a motivos internos (por exemplo, “ela está triste”. “este menino está doente”, “ela está zangada" e apenas $14 \%$ atribui a motivos contextuais (por exemplo, "porque não quer jogar à bola”, "por causa de um brinquedo", “está agarrado na parede”) e $27 \%$ não atribuiu causa ao conflito.

Na previsão de acontecimentos verificou-se que a maioria das crianças (68\%) conseguiu indicar uma previsão (por exemplo, “a menina vai continuar sozinha"; "ela vai querer brincar com elas"; "vai encontrar uma menina para brincar”; "não vai gritar mais”; "vai continuar a gritar muito"; "o educador vai pô-lo de castigo”; “vão dar um abraço um ao outro”; “vão ficar zangados”; “vão fazer as pazes”) e 32\% não indicou uma previsão.

A nível da identificação das emoções constatou-se que a maioria das crianças do estudo consegue identificar as emoções (80\%), no entanto $20 \%$ das crianças não identifica nenhuma emoção. Das crianças que identificam as emoções $41 \%$ não identificaram a emoção esperada, mas identificaram outras emoções, como por exemplo, “zangada”, “contente”, “chateada”.

Na conceção de um plano para a solução do problema verificou-se que $41 \%$ das crianças apresentou uma solução vaga (por exemplo, “ia com a mamã”, “ia para a praia”, "ia dizer ao Carlos", "ficava toda a manhã até ir almoçar sempre a chorar”, "ia para a rua”), 33\% não apresentou nenhuma solução para o problema e apenas 26\% é que apresentou uma solução alternativa (por exemplo, "ia brincar com outros amigos", "ia conversar com as meninas”, "pedia desculpa ao amigo”, “dava-lhe um abraço", "ia dizer à professora e ele ficava de castigo", "fazia as pazes").

A nível da compreensão emocional: emoções negativas e emoções positivas $47 \%$ das crianças não regula as emoções, 32\% relaciona emoções negativas a situações negativas, porque souberam indicar que seria mais difícil resolver a situação, se estivessem zangados e $21 \%$ relaciona emoções positivas a situações positivas, porque indicaram que seria mais fácil resolver a situação se estivessem mais calmos. Podemos constatar que quase metade da amostra das crianças não consegue regular as emoções, demonstram dificuldade em perceber que existe uma relação entre as nossas reações consoante as situações positivas ou negativas.

Nas estratégias futuras: Apresentação de soluções para situações negativas e positivas 34\% das crianças apresenta uma solução diferente para as situações 
Tabela 1

Questões, critérios de categorização e cotação das entrevistas

\begin{tabular}{|c|c|c|}
\hline Questões & Categorias & Subcategorias \\
\hline \multirow{3}{*}{$\begin{array}{l}\text { 1- O que achas } \\
\text { que está a } \\
\text { acontecer nesta } \\
\text { imagem? }\end{array}$} & \multirow{3}{*}{$\begin{array}{l}\frac{\text { Identificaçã }}{\text { o do Conflito }} \\
\text { Na resposta } \\
\text { analisar se a } \\
\text { criança } \\
\text { identifica o } \\
\text { conflito } \\
\text { esperado ou } \\
\text { outro conflito. }\end{array}$} & $\begin{array}{l}\text {-Não identifica } \\
\text { conflito (Não sei, estão a } \\
\text { brincar) }\end{array}$ \\
\hline & & 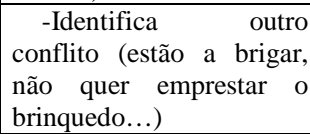 \\
\hline & & 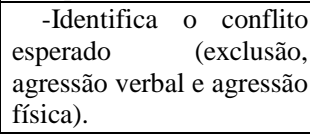 \\
\hline \multirow{4}{*}{$\begin{array}{l}\text { 2- Para } \\
\text { olhaste } \\
\text { perceber o qara } \\
\text { está a acontecer? }\end{array}$} & \multirow{4}{*}{\begin{tabular}{lr}
\multicolumn{2}{r}{ Descodific } \\
ação Causal \\
\multicolumn{2}{c}{ Na resposta } \\
analisar como \\
é que a \\
criança \\
descodifica os \\
conflitos, se \\
através de \\
estímulos do \\
contexto, se \\
através \\
expressões de \\
faciais ou se \\
através \\
expressões de \\
faciais \\
estímulos do \\
contexto.
\end{tabular}} & $\begin{array}{l}\text {-Não } \begin{array}{l}\text { descodifica a } \\
\text { causa (Indicar outras } \\
\text { causas, não responder) }\end{array} \\
\end{array}$ \\
\hline & & $\begin{array}{l}\text { - Descodifica as causas } \\
\text { através de expressões } \\
\text { faciais (Apontar ou referir } \\
\text { a cara, os olhos, a boca) }\end{array}$ \\
\hline & & $\begin{array}{l}\text { - Descodifica as causas } \\
\text { através de estímulos do } \\
\text { contexto (Apontar ou } \\
\text { referir o que as figuras das } \\
\text { imagens estão a fazer) }\end{array}$ \\
\hline & & $\begin{array}{l}\text { - Descodifica as causas } \\
\text { através de expressões } \\
\text { faciais e estímulos do } \\
\text { contexto (Apontar ou } \\
\text { referir a cara, os olhos, a } \\
\text { boca e o que as figuras das } \\
\text { imagens estão a fazer) }\end{array}$ \\
\hline \multirow{5}{*}{$\begin{array}{l}\text { 3- } r \text { Porque } \\
\text { achas que isto } \\
\text { aconteceu? }\end{array}$} & \multirow{5}{*}{$\begin{array}{l}\text { Atribuição } \\
\frac{\text { causal do }}{\text { conflito }} \\
\text { Na resposta } \\
\text { analisar se a } \\
\text { criança atribui } \\
\text { uma causa ao } \\
\text { conflito e se } \\
\text { indica se este } \\
\text { é devido a } \\
\text { motivos } \\
\text { contextuais, } \\
\text { motivos } \\
\text { internos ou } \\
\text { motivos } \\
\text { relacionais. }\end{array}$} & -Não atribui causa ao \\
\hline & & \\
\hline & & $\begin{array}{l}\text { contextuais (Quando as } \\
\text { causas são atribuídas aos } \\
\text { fatores de contexto) }\end{array}$ \\
\hline & & \begin{tabular}{lll} 
& \multicolumn{1}{c}{-Atribui a motivos } \\
internos (Quando as & a \\
causas são atribuídas às \\
emoções das crianças)
\end{tabular} \\
\hline & & 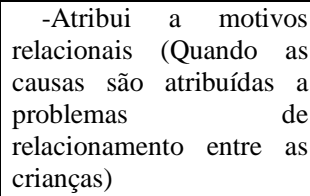 \\
\hline \multirow{3}{*}{$\begin{array}{l}\text { 4- O que achas } \\
\text { que depois vai } \\
\text { acontecer? }\end{array}$} & \multirow{3}{*}{$\begin{array}{l}\text { Previsão de } \\
\text { aconteciment } \\
\underline{\text { os }} \\
\text { Na resposta } \\
\text { analisar se a } \\
\text { criança } \\
\text { consegue } \\
\text { prever o que } \\
\text { vai acontecer } \\
\text { depois da } \\
\text { situação que } \\
\text { lhe foi } \\
\text { apresentada. }\end{array}$} & -Não \\
\hline & & previsão \\
\hline & & $\begin{array}{l}\text {-Indica uma previsão } \\
\text { (Indica o que vai acontecer } \\
\text { depois da situação de } \\
\text { conflito) }\end{array}$ \\
\hline \multirow[t]{2}{*}{$\begin{array}{l}\text { 5- Como achas } \\
\text { que se sente a } \\
\text { pessoa que foi } \\
\text { agredida? }\end{array}$} & \multirow{2}{*}{$\begin{array}{l}\text { Identificaçã } \\
\text { o das emoções } \\
\text { Na resposta } \\
\text { analisar se a } \\
\text { criança } \\
\text { identifica a }\end{array}$} & 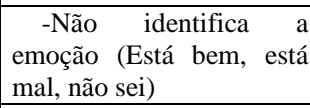 \\
\hline & & \begin{tabular}{lr}
\multicolumn{1}{c}{-Identifica } & $\begin{array}{r}\text { outra } \\
\text { emoção }\end{array}$ \\
felicidade) & (Alegria,
\end{tabular} \\
\hline
\end{tabular}

\begin{tabular}{|c|c|c|}
\hline & \begin{tabular}{|l|l|} 
emoção & \\
esperada & ou \\
outras & \\
emoções. & \\
\end{tabular} & $\begin{array}{l}\text {-Identifica a emoção } \\
\text { esperada (triste, zangado) }\end{array}$ \\
\hline \multirow{3}{*}{$\begin{array}{l}\text { 6- Imagina que } \\
\text { és o menino (a) } \\
\text { da imagem. } \\
\text { Como } \\
\text { resolve-rias a } \\
\text { situação? }\end{array}$} & \multirow{3}{*}{\begin{tabular}{|l}
$\frac{\text { Conceção }}{\text { de plano }}$ \\
para a solução \\
$\frac{\text { do problema }}{\text { Na resposta }}$ \\
analisar se a \\
criança \\
con-segue \\
apre-sentar \\
uma solução \\
alternativa \\
para resolver a \\
situação que \\
lhe foi \\
apresentada.
\end{tabular}} & $\begin{array}{l}\text {-Não apresenta solução } \\
\text { para o problema }\end{array}$ \\
\hline & & $\begin{array}{l}\text {-Apresenta uma solução } \\
\text { vaga (Indica uma solução } \\
\text { pouco eficaz) }\end{array}$ \\
\hline & & $\begin{array}{l}\text {-Apresenta soluções } \\
\text { alternativas (Indica uma } \\
\text { solução alternativa para } \\
\text { resolver a situação) }\end{array}$ \\
\hline \multirow{2}{*}{$\begin{array}{lr}\text { 7- } & \text { Se } \\
\text { estivesses } \\
\text { zangado (a), seria } \\
\text { mais fácil ou } \\
\text { mais difícil } \\
\text { aplicar a tua } \\
\text { estratégia? }\end{array}$} & \multirow[b]{2}{*}{ 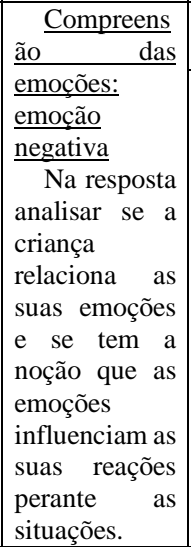 } & -Não regula as emoções \\
\hline & & $\begin{array}{l}\text {-Relaciona } r \text { emoções } \\
\text { negativas a situações } \\
\text { negativas (Refere que } \\
\text { quando está zangado é } \\
\text { mais difícil aplicar a sua } \\
\text { estratégia) }\end{array}$ \\
\hline \multirow{3}{*}{$\begin{array}{l}\text { 8- E mudavas } \\
\text { alguma coisa? O } \\
\text { que farias de } \\
\text { diferente? }\end{array}$} & \multirow{3}{*}{$\begin{array}{l}\text { Estratégias } \\
\text { futuras: } \\
\text { Apresentação } \\
\text { de soluções } \\
\text { para situações } \\
\text { negativas }\end{array}$} & -Não muda \\
\hline & & $\begin{array}{l}\text {-Apresenta uma solução } \\
\text { diferente (Refere uma } \\
\text { solução diferente que pode } \\
\text { solucionar a situação) }\end{array}$ \\
\hline & & $\begin{array}{l}\text {-Muda (Refere que } \\
\text { muda, mas não indica o } \\
\text { que mudava ou o que faria } \\
\text { de diferente, apresenta } \\
\text { uma solução vaga) }\end{array}$ \\
\hline \multirow{3}{*}{\begin{tabular}{l}
\multicolumn{1}{c}{$10-$} \\
estivesses calmo, \\
seria mais fácil \\
ou mais difícil \\
aplicar a tua \\
estratégia?
\end{tabular}} & \multirow[b]{3}{*}{ 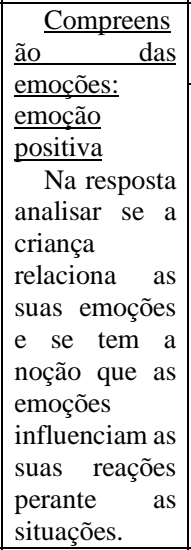 } & -Não regula as emoções \\
\hline & & \\
\hline & & $\begin{array}{l}\text {-Relaciona emoções } \\
\text { negativas a situações } \\
\text { negativas (Refere que } \\
\text { quando está mais calmo é } \\
\text { mais fácil aplicar a sua } \\
\text { estratégia) }\end{array}$ \\
\hline \multirow{3}{*}{$\begin{array}{l}\text { 11- E mudavas } \\
\text { alguma coisa? O } \\
\text { que farias de } \\
\text { diferente? }\end{array}$} & \multirow{3}{*}{$\begin{array}{l}\text { Estratégias } \\
\text { futuras: } \\
\text { Apresentação } \\
\text { de soluções } \\
\text { para situações } \\
\text { positivas }\end{array}$} & Não muda \\
\hline & & $\begin{array}{l}\text {-Apresenta uma solução } \\
\text { diferente (Refere uma } \\
\text { solução diferente que pode } \\
\text { solucionar a situação) }\end{array}$ \\
\hline & & $\begin{array}{l}\text {-Muda (Refere que } \\
\text { muda, mas não indica o } \\
\text { que mudava ou o que faria } \\
\text { de diferente, apresenta } \\
\text { uma solução vaga) }\end{array}$ \\
\hline
\end{tabular}


problema apresentadas (por exemplo, "ia procurar um amigo só meu”, "ia conversar com elas”, “aproximava elas todas", "eu dizia a todos os amigos para irem à minha casa", "fazer as pazes", "ia brincar com os meninos”, "os amigos abraçavam-se um ao outro", "pedia desculpa”), 24\% afirma que mudava alguma coisa, mas não refere o quê e $42 \%$ não mudava nada e nem indica uma solução diferente.

\section{Relação entre a compreensão emocional e a capacidade de gestão de conflitos}

$\mathrm{Na}$ tabela 2 observamos que a compreensão emocional quando avaliada pelo TEC está positivamente correlacionada com a capacidade de identificar conflitos $(r=.45, p=.018)$. Quanto maior a compreensão das emoções, maior é a capacidade para identificar conflitos. Também encontramos correlações marginalmente significativas com a capacidade global de gestão de conflitos $(r=.35, p=.070)$. É importante frisar que segundo a análise desta amostra, a compreensão emocional avaliada pelo TEC não está correlacionada com a capacidade de compreensão das emoções em situações de conflito.

Mais especificamente, a componente 5 da compreensão das emoções (compreensão da influência da lembrança em circunstâncias de avaliação dos estados emocionais) está correlacionada positivamente com a gestão global de conflitos $(r=.41, p=.036) \mathrm{e}$ especificamente a dimensão da identificação de conflitos $(r=.51, p=.006)$. (Ver tabela 9).

Podemos verificar também que a componente 9 (compreensão das expressões morais) estava marginalmente correlacionada com a identificação de conflitos $(r=.36, p=.067)$. Parece indicar que uma maior compreensão das expressões morais poderia levar a uma maior capacidade de identificação de conflitos.

\section{Tabela 2}

Resultados do teste de correlação de Pearson entre a compreensão emocional e a gestão de conflitos

\begin{tabular}{|c|c|c|c|c|c|c|c|c|c|c|}
\hline & TEC & 1 & 2 & 3 & 4 & 5 & 6 & 7 & 8 & 9 \\
\hline $\begin{array}{l}\text { Gestão de } \\
\text { conflitos } \\
\text { global }\end{array}$ & .35 & . & . & $\begin{array}{l}.1 \\
9\end{array}$ & -.01 & $\begin{array}{l}.41 \\
*\end{array}$ & .07 & $\begin{array}{l}.2 \\
3\end{array}$ & .09 & .24 \\
\hline $\begin{array}{l}\text { Identifi- } \\
\text { cação de } \\
\text { Conflitos }\end{array}$ & $.45^{*}$ & . & . & $\begin{array}{l}.2 \\
1\end{array}$ & -.01 & $\begin{array}{l}.51 \\
* *\end{array}$ & .10 & $\begin{array}{l}.2 \\
1\end{array}$ & .11 & .36 \\
\hline $\begin{array}{l}\text { Compre- } \\
\text { ensão das } \\
\text { Emoções }\end{array}$ & .20 & . & . & $\begin{array}{l}.0 \\
3\end{array}$ & .08 & .31 & $\begin{array}{l}-.0 \\
7\end{array}$ & $\begin{array}{l}.1 \\
4\end{array}$ & .21 & $\begin{array}{l}-.1 \\
0\end{array}$ \\
\hline $\begin{array}{l}\text { Gerar } \\
\text { soluções }\end{array}$ & .17 & . & . & $\begin{array}{l}.1 \\
9\end{array}$ & .06 & .14 & .08 & $\begin{array}{l}.2 \\
1\end{array}$ & $\begin{array}{l}-.0 \\
7\end{array}$ & .20 \\
\hline
\end{tabular}

Nota. $\mathrm{n}=27$; a. Não pode ser calculada porque todas as crianças responderam corretamente esta componente; Componentes do TEC: $1=$ Reconhecimento, 2 = Causa Externa, 3 = Desejo, 4 = Crença, $5=$ Lembrança, $6=$ Regulação, $7=$ Esconder, 8 = Misto, $9=$ Moralidade.

\section{Discussão}

Neste estudo verificou-se que a maioria das crianças foram capazes de identificar as situações de conflito que observaram nas imagens que lhes foram facultadas, bem como é capaz de reconher as causas que os provacam e o previsível curso das situações.. A nível emocioanla foram também capazes de identificar as emoções das personagens e as suas possiveis causas, como seria de esperar (Denham, 1998). As maiores dificuldades surgem na conceção de estratégias de resolução dos conflitose na gestão emocional.

Quanto à relação entre a compreensão emocional e a capacidade de resolução de conflitos, o melhor desempenho na compreensão das emoções justifica-se pelo fato das crianças aprenderem primeiro a reconhecer emoções e só depois é que conseguem encontrar soluções para os problemas. Quanto maior a compreensão das emoções, maior é a capacidade para identificar conflitos. Este resultado vai de encontro à perspetiva de Denham (1998) que afirma que as crianças que percebem melhor as emoções têm mais relações positivas nas suas interações com os pares. Os que percebem as emoções dos outros, interagem com mais sucesso, quando um amigo se magoa ou está zangado. A criança que consegue falar das suas emoções é também melhor a negociar as disputas entre os seus pares.

Hartup (1996) sugere que o grupo de pares constitui um dos contextos de maior socialização, no qual cada indivíduo aprende a comportar-se de forma socialmente competente. Por conseguinte, ao interagir com os pares, este, vai criar uma plasticidade suficiente para se adaptar a situações de stress (Funder \& Block, 1989), desenvolvendo a capacidade de controlar as suas motivações imediatas e de expressar adequadamente as emoções, ao mesmo tempo que consegue estabelecer interações sociais favoráveis e estáveis (Waters \& Sroufe, 1983).

Resumindo, observamos que as crianças em idade pré-escolar podem nomear e reconhecer expressões para a maioria das emoções básicas e identificar situações comuns que provocam emoções. Elas podem falar sobre as causas das emoções e estão a ficar mais conscientes da influência das crenças, dos desejos e das lembranças nas emoções. Elas estão apenas a começar a entender regulação da emoção, as regras de exibição, a simultaneidade, e ambivalência. No entanto, existem certos limites para a compreensão das emoções nas crianças do pré-escolar, pois muitas vezes permanecem apegados as causas externas ao interpretar emoções, que necessariamente prejudicam a sua precisão.

\section{Referencias}

Aureli, F., Cords, M. \& Van Schaik, C. P. (2002). Conflict resolution following aggression in gregarious animals: a predictive framework. Animal Behaviour, 64, 325-343.

Denham, S. (1998). Emotional development in young children. New York: Guilford Press.

Denham, S. A. (2007). Dealing with feelings: How children negotiate the worlds of emotions and social relationships. Cognition, Brain, Behaviour, 11, 1-48.

Denham, S. A., \& Couchoud, E. (1990). Young preschoolers' understanding of emotions. Child Study Journal, 20, 171-192.

Funder, D. \& Block, J. (1989). The role of ego-control, ego-resiliency, and IQ in delay of gratification in 
adolescence. Journal of Personality and Social Psycology, vol. 57 (6), 1041-1050.

Green, V. A. \& Rechis, R. (2006). Children's cooperative and competitive interactions in limited resource situations: a literature review. Applied Developmental Psychology, 27, 42-59.

Harris, P. (1989). Children and emotion. The development of psychological undestanding. Oxford: Blackwell Publishers.

Hartup, W. (1983). Peer relations. In E. M. Hetherington (Ed.), P. H. Mussen (Series Ed.), Handbook of child psychology. Socialization, personality and social development, 3, 103-198. New York: Wiley.

Hartup, W. W., Laursen, B., Stewart, M. I., \& Eastenson, A. (1988). Conflict and the friendship relations of young children. Child Development, 59, 1590-1600.

Hartup, W. W. (1992). Conflict and relations. In C.U. Shantz, W. W. Hartup (Eds.) Conflict in Child and adolescent development. Cambridge, UK: Cambridge University Press, 186-215.

Hartup, W. W. (1996). The company they keep: Friendships and their development significance. Child Development, 67, 1-13.

Hawley, P. H. (1999). The ontogenesis of social dominance: a strategy-based evolutionary perspective. Development Review, 19, 97-132.

Hollos, M. \& Cowan, P. A. (1973). Social Isolation and Cognitive Development: logical operations and role-taking abilities in three nowergian social settings. Child development, 44, 630-641.
Pons, F., \& Harris, P. (2005). Longitudinal change and longitudinal stability of individual differences in childrens' emotion understanding. Cognition and Emotion, 19, 1158-1174.

Preuschoft, S., Wang, X., Aureli, F., \& de Waal, F. (2002). Reconciliation in captive chimpanzees: A reevaluation with controlled methods. International Journal of Primatology, 23 (1), 29-50.

Rubin, K. H., Bukowski, W., \& Parker, J. G. (1998). Peer interactions, relationships, and groups. In W. Damon (Series Ed.) N. Eisenberg (Vol. Ed.), Hanbook of Child Psychology. Social, emotional, and personality development. (Vol.3, pp. 619-700). New York: Wiley.

Shantz, C. U. (1987). Conflicts between children. Child Development. 58, 283-305.

Verbeek, P. \& de Waal, F. B. M. (2001). Peacemaking among preschool children. Jornal of Peace Psychology, 7, 5-28.

Walker, S. (2005). Gender differences in the relationship between young children's peer related social competence and individual differences in theory of mind. The Journal of Genetic Psychology, 166 (3), 297-312.

Waters, E. \& Srouf, L. A. (1983). Social competence as a development construct. Developmental Review, 3, 79-97.

Wellman, H. M., Cross, D. \& Watson, J. (2001). Meta-analysis of theory-of-mind development: The truth about false belief. Child Development, 72, 655-684. 